\title{
EDITORIAL
}

\section{Severe asthma is an epithelial disease}

\author{
P. Chanez
}

$\triangle 1$ sthma is an important, clinically prevalent disease worldwide. Despite a better knowledge on the pathogenesis, the mechanisms underlying the induction and persistence of the disease are largely unknown. It is now accepted that airway inflammation and structural changes of the bronchi are important features. The relationships between those structural changes and clinical and functional abnormalities clearly deserved further investigations. These findings led to the reinforcement of the use of inhaled corticosteroids as the pivotal treatment for asthma. Nevertheless, there are still patients who have persistent symptoms, altered lung function and a high rate of exacerbations, despite long-term specialist follow-up and continuous optimal treatment. These severe patients have a major handicap in their daily life and are responsible for most of the costs created by asthma [1]. Therefore, it is of major importance to better understand the mechanisms leading to this severe phenotype.

Almost one century ago, ELLIS [2] highlighted that the pathology of asthma could be investigated by examining sputum from living patients or the lungs of patients who die during an attack. From these sources, the role of bronchial epithelium was clarified by describing elongated epithelial cells in the sputum and the presence of abnormalities of the pseudo-stratified and ciliated epithelium in most fatal cases, albeit it varied considerably as regards location and extent [2]. The role played by epithelial cells was revisited in more detail only $15 \mathrm{yrs}$ ago, and their response to inflammation and damage have been clearly found to be abnormal in asthma [3].

Allergens are potential deleterious factors that may interact and injure bronchial epithelium, leading to the development of long-term diseases such as asthma. In a study using an in vivo provocation test, they have been shown to interfere with bronchial epithelium homeostasis by inducing proliferation [4]. Viral infections are well-known inducers of most of the asthma exacerbations in children and adults. They interact with the bronchial epithelium and participate to the structural changes of the airways, leading to bronchial hypersecretion and hyperreactivity, lasting $\geqslant 1 \mathrm{yr}$ in some animal models, mimicking the persistence of the human disease [5]. Several different mechanisms that are linked to inflammation induce epithelial damage in asthma. Mediators issued from inflammatory cells, such as cationic proteins, various proteolytic enzymes, metalloproteinases and oxygen reactive species, are potential culprits. Bronchial oedema and vascular leakage participate towards the fragility of the epithelium layer in the

CORRESPONDENCE: P. Chanez, Clinique des Maladies Respiratoires, Hôpital Arnaud de Villeneuve, 371 Av. Du Doyen Gaston Giraud, 34295 Montpellier Cedex 5, France. Fax: 33 467521848. E-mail: chanez@montp.inserm.fr asthmatic bronchi. Early repair processes try to restore the integrity of the tissue. The dynamics of these events are complex, including cell activation and death, but also proliferation, migration and differentiation. The repairing epithelium produces various growth factors that are able to activate structural cells from the submucosa, including fibroblasts and smooth muscle cells. This cell-to-cell cooperation led some authors to postulate that the structural changes of the airways seen in asthma are due to the reactivation of the epithelial mesenchymal trophic unit, which controls the morphogenesis of the airway in the antenatal life [6].

In asthma, the bronchial epithelium is modified and appears fragile and activated. Abnormalities include the loss of the most superficial layer of the epithelium, destruction of ciliated cells, upregulation of growth-factor release, and the overexpression of receptors, such as epidermal growth factor receptors (EGFR). The gross morphology of the epithelium observed on endobronchial biopsies has been controversial. The shedding of the epithelium, reported earlier by investigators looking at endobronchial biopsies, is now thought to be due, at least in part, to the sampling procedure. Despite this potential confounding factor, the fragility of the epithelium remains a reality [7]. No single study has demonstrated the ability of inhaled corticosteroids to restore a complete normal epithelial layer [8].

In this issue of the European Respiratory Journal, HAMILTON et al. [9] report the alteration of epithelial tyrosine phosphorylation of bronchial epithelial cells obtained at fibreoptic bronchoscopy in living asthmatics with a severe form of the disease. Endobronchial biopsies or explanting brushed cells were used to analyse different signalling pathways. Of interest, those changes were rather unique for the cells from severe patients as compared with normal subjects and patients with a milder form of the disease. Phosphotyrosine levels were not affected by a 6-week treatment with inhaled corticosteroids. The epidermal growth factor, tyrosine kinase, was found to be upregulated in the epithelium of severe asthmatics, and in vitro experiments demonstrated the inability of corticosteroids to suppress the phosphorylation of EGFR and several downstream or associated proteins, such as mitogen-activated protein kinase.

In severe asthma, the expression of receptors, such as EGFR, is upregulated and not affected by current treatments, including corticosteroids [10]. Cell survival and proliferation markers are co-expressed with markers of activation, such as nuclear factor- $\kappa \mathrm{B}$, in the epithelium of endobronchial biopsies obtained from cortico-dependent patients. In severe asthma patients, the epithelium layer was thicker than in patients with mild disease, and few apoptotic cells were identified. This study was important to suggest that, in severe asthma, epithelial cells 
were associated with an abnormal repair process, despite the absence of epithelial desquamation [10]. Of note, the upregulation of the cyclin-dependent kinase inhibitor, p21WAF, in asthmatic epithelium may contribute to this prolonged activation, despite the absence of loss of control of this proliferation [11]. This enzyme regulates the proliferation rate of the cells and is unaffected by the corticosteroids. It can be induced by various mediators and growth factors, including transforming growth factor- $\beta$, which was found to be overproduced in asthmatic airways [12]. The combination of endobronchial biopsies analysis with the results obtained ex vivo using primary cultures of brushed epithelial cells contributes towards establishing epithelial abnormalities as a potential intrinsic factor in the pathophysiology of severe asthma.

The resolution of inflammation is a highly coordinated, active process that is controlled by endogenous anti-inflammatory mediators. These mediators may switch off the chemoattraction and activation of leukocytes and reverse vascular abnormalities. Transcellular metabolism of arachidonic acid by lipoxygenase interaction gives rise to the lipoxin family of eicosanoid metabolites. Bronchial epithelium is rich in 15 lipoxygenase-derived products, indicating its potential as a source for those natural anti-inflammatory products. Severe asthma was recently found to be associated with a loss in lipoxin-A4 production as compared with mild, controlled asthma [13]. Lipid mediators are then potentially essential components of inflammation resolution, avoiding further amplification leading to tissue remodelling. These findings provide some rationale for developing stable mimetics, which can affect key aspects of chronic inflammation in asthma.

These data contribute towards highlighting the epithelium as a crucial partner in severe asthma, and may indicate bronchial epithelial intracellular signalling pathways as potential targets for new therapeutic interventions when glucocorticoids and long-acting $\beta_{2}$-agonists are of limited efficacy.

\section{REFERENCES}

1 Godard P, Chanez P, Siraudin L, Nicoloyannis N, Duru G. Costs of asthma are correlated with severity: a 1-yr prospective study. Eur Respir J 2002; 19: 61-67.

2 Ellis AG. The pathological anatomy of bronchial asthma. Am J Med Sci 1908; 136: 407-429.
3 Campbell AM, Chanez P, Vignola AM, et al. Functional characteristics of bronchial epithelium obtained by brushing from asthmatic and normal subjects. Am Rev Respir Dis 1993; 147: 529-534.

4 Ricciardolo FL, Di Stefano A, van Krieken JH, et al. Proliferation and inflammation in bronchial epithelium after allergen in atopic asthmatics. Clin Exp Allergy 2003; 33: 905-911.

5 Walter MJ, Morton JD, Kajiwara N, Agapov E, Holtzman MJ. Viral induction of a chronic asthma phenotype and genetic segregation from the acute response. J Clin Invest 2002; 110: 165-175.

6 Holgate ST, Lackie PM, Howarth PH. Activation of epithelial mesenchymal trophic unit in the pathogenesis of asthma. Int Arch Allergy Immunol 2001; 124: 253-258.

7 Bousquet J, Jeffery PK, Busse WW, Johnson M, Vignola AM. Asthma. From bronchoconstriction to airways inflammation and remodeling. Am J Respir Crit Care Med 2000; 161: 1720-1745.

8 Lundgren R, Soderberg M, Horstedt P, Stenling R. Morphological studies of bronchial mucosal biopsies from asthmatics before and after ten years of treatment with inhaled steroids. Eur Respir J 1988; 1: 883-889.

9 Hamilton LM, Puddicombe SM, Dearman RJ, et al. Altered protein tyrosine phosphorylation in asthmatic bronchial epithelium. Eur Respir J 2005; 25: 978-985.

10 Vignola AM, Chiappara G, Siena L, et al. Proliferation and activation of bronchial epithelial cells in corticosteroiddependent asthma. J Allergy Clin Immunol 2001; 108: 738-746.

11 Puddicombe SM, Torres-Lozano C, Richter A, et al. Increased expression of p21waf cyclin-dependent kinase inhibitor in asthmatic bronchial epithelium. Am J Respir Cell Mol Biol 2003; 28: 61-68.

12 Chakir J, Shannon J, Molet S, et al. Airway remodellingassociated mediators in moderate to severe asthma: effect of steroids on TGF- $\beta$, IL-11, IL-17, and type I and type III collagen expression. J Allergy Clin Immunol 2003; 111: 1293-1298.

13 Vachier I, Bonnans C, Chavis C, et al. Severe asthma is associated with a loss of LXA4, an endogenous antiinflammatory compound. J Allergy Clin Immunol 2005; 115: $55-60$. 